\title{
Barriers to E-Commerce Adoption among SMEs in Sierra Leone: The Moderating Role of Geographical Location
}

\author{
Abdulai S. Brima ${ }^{\# 1}$, Brima Sesay ${ }^{* 2}$ \\ ${ }^{\#}$ Head of Department, Department of Economics and Commerce, Fourah Bay College, University of Sierra \\ Leone \\ "Lecturer, School of Economics, Wuhan University of Technology, Wuhan, China.
}

\begin{abstract}
E-commerce implementation by businesses in developing countries are faced with substantially greater challenges than businesses in developed countries due to the unreliability of the internet connection, the poor availability of accessing it due to the poor infrastructure, the high cost of doing so, and also the low level of ICT penetration. This study explored the barriers to e-commerce adoption among SMEs in Sierra Leone and came up with solid policy implications as to how to mitigate those challenges that need to be overcome for the success of e-commerce adoption. The main purpose of the research was to identify the most challenging barriers to e-commerce adoption and in the process investigate their moderating effect of geographical location for SMEs. A survey was done to collect 442 usable questionnaires from registered SMEs owners in the capital city and three major rural districts (Bo, Kenema and Makeni) of Sierra Leone. Persons' correlation and multiple linear regression models were used to test the hypotheses of the study. The Results of correlation analysis showed that technological, organizational and environmental barriers are statistically significant and negatively correlated with e-commerce adoption. The results further showed that technological barrier is the most challenging barrier to e-commerce adoption. Similarly, the moderating effects of geographical locations were tested using regression analysis. The key finding is that, all the predictors have a more negative effect on e-commerce adoption for rural SMEs compared with urban SMEs. Based on the results, the study concluded with making a call for the Sierra Leone authorities, policy makers, entrepreneurs, and SMEs managers to offer conducive business environment, and focus more attention to rural SMEs for expanding their e-commerce adoption capacity.
\end{abstract}

Keywords - E-commerce adoption; Technological barriers; Organisational barriers; Environmental barriers; Geographical Location

\section{INTRODUCTION}

This study investigates the barriers to e-commerce adoption among SMEs in Sierra Leone. The moderating effect of geographical location is also accounted for in the model. Given the growing recognition of the internet and communication technologies and the increasing consumer's enquiry and purchase on the internet, this research is timely and significant. Tamilla Mavlanova (2014) had predicted that by 2017 business-to-consumer electronic commerce sales revenue will reach about \$2.36 trillion. Growing internet commerce applications significantly reduce the cost of conducting and operating a business (Cindy Millman, et. al., 2009). Consequently, the thriving electronic commerce creates an opportunity for internet entrepreneurship. Although the promise on the high potential and low cost of e-commerce startup attracts entrepreneurs but the success rate is usually too low (Brian Foster, 2013). The significant role of e-commerce for growth and development has received much interest in literature in recent years. Various studies have tackled this issue but there is still a gap to be filled, especially for Sierra Leone.

Information and communication technologies (ICT), particularly e-commerce, are considered very important to the Sierra Leone economy, as a result Sierra Leone should seek to enact legislation to enable and encourage the adoption of e-commerce. In addition, there has been proliferation of telecommunication companies in Sierra Leone providing Internet services as a way of encouraging businesses, especially SMEs, to adopt e-commerce. However, little is known about SMEs e-commerce activities. Also, there has been number of studies on the adoption of e-commerce solutions by SMES (Molla and Licker 2005; Tan, Tyler, \& Manica, 
2007), these studies identified some challenges envisaged by businesses in adopting e-commerce in developed countries. There is therefore the need for a study that will look at African situation in general and Sierra Leone context in particular.

In Sierra Leone, e-commerce use among SMEs is a new phenomenon. Even though the issue of ecommerce has been adopted by large companies, but it adoption by SMEs has been very slow and consequently demands great attention.

Furthermore, e-commerce has become an indispensable means of doing business. The opportunities it offers are so great that it would appear that there is no going back. In addition, literature is replete with how both developed and developing countries have adopted e-commerce. Like many Sub-Saharan African countries, the Sierra Leone government is aware of this fact. However, due to low penetration of internet and lack of adequate information technology infrastructures, adoption of e-commerce has been taking place at a snail's pace. At the moment very few Sierra Leoneans have access to the Internet and that negatively affects the adoption of ecommerce.

This study is different from previous studies in several ways; first, it aggregated the factors that affect ECommerce adoption into three major factors (technological, organisational and environmental). Second, the study accounted for the moderating role of geographical location which has also been neglected in previous studies of this nature. Several relevant recommendations are provided to the Sierra Leone authorities and policy makers, entrepreneurs, and SME managers to ascertain the appropriate strategy to mitigate the most prominent factors constraining the adoption of e-commerce by SMEs.

\section{LITERATURE REVIEW AND THEORETICAL FRAMEWORK}

\subsection{Literature Review}

Electronic commerce, commonly known as e-commerce, is trading in products or services using computer networks, such as the Internet. It is undeniable that e-commerce has changed the way in which business is conducted; it has not only changed the way people sell, purchase or deal with their customers and suppliers but it has also changed the business perspective from "production excellence" to "customer intimacy" (Macgregor \& Vrazalic, 2005) and from being "agent of seller" to being "agent of buyer" (Achrol \& Kotler, 1999), and the business focus from physical goods alone to a service, information and intelligence focus (Rayport \& Jaworski, 2001). As a result, the new economy era - the information era - has been created. As of now, almost all both developed and developing countries are enhancing the diffusion and adoption of e-commerce. It is a pity that most African countries, including Sierra Leone are lagging behind in this.

Electronic commerce activities are related to mobile communication, electronic funds transfer, supply chain management, internet marketing, online transaction processing, electronic data interchange (EDI), inventory management systems, and automated data collection systems. In the simplest case, it can be defined as doing business transactions in an electronic format (Shahriari, Shahriari \& Saeid, 2015). As aforementioned discussion, most governments have adopted e-commerce as one of their priorities. For instance according to Rahayu and Day (2015) report, many countries have given considerable attention to the adoption of e-commerce through issuing policies and regulations to assist Small and Medium Enterprise (SMEs) to conduct e-commerce; for example, in Australia, several programs and ICT policies, such as The Building on IT Strengths (BITS) Incubator program; the National Technology Online program(ITOL); have been instituted to facilitate ecommerce adoption by SMEs (OECD, 2002). Similar programs are also found in countries such as Austria with the "Let's e Biz" program; Finland with the "eASKEL" program; the Netherlands with "Netherland go Digital" program; Sweden with the "SVEA" program; Luxembourg with the "APSI/CRP-HT Guide" program; and Ireland with "PRISM initiative" program (OECD, 2002).

E-commerce has so many advantages in our lives because it makes convenience to people in daily life. Several scholars have been proposed for e-commerce that most of them are based on past experiences in the use of e-commerce. Today, major corporations are rethinking their businesses in terms of the internet and its new culture and capabilities and this is what some see as e-business (Shahriari, Shahriari \& Saeid, 2015).

Despite these advantages, diffusion and adoption of e-commerce is very low in African countries. Invariably, businesses implementing e-commerce in developing countries (such as African countries) face substantially greater challenges than businesses in developed countries due to the unreliability of the internet connection, the poor availability of accessing it due to the poor infrastructure, the high cost of doing so, and also the low level of ICT penetration throughout the country. (Molla \& Licker, 2005b; Molla \& Licker, 2005a; Aleid, 
2009), carried out an investigation of different e-commerce schemes in a number of countries with regard to culture, infrastructure and human behavior. They find that there are a number of factors that may inhibit the diffusion of e-Commerce into developing countries such as infrastructure, security, e-Commerce laws (cited in Kabango \& Asa, 2015).

Furthermore, in-spite of the opportunities e-commerce presents, it also has poses certain challenges which are sometimes too much to handle for start-ups: internet is the backbone of e-commerce. For example, in many developing countries internet penetration is so far dismally low at 0.5 per cent of the population, penetration of personal computer (PC) as low as 3.5 per thousand of population and penetration of telephone only 2.1 per cent of population, ecommerce is not easily reachable remains to the common man (Rina, 2016).

The above paragraph clearly paints a picture that there is a huge digital divide between developed and developing countries in as far as diffusion and adoption of e-commerce is concerned. Many studies have therefore, recommended that it is incumbent upon governments to be vigilant in promoting diffusion and adoption of e-commerce. Molla and Licker (2005), state that the government demonstrates strong commitment to promoting e- commerce.

In Saudi Arabia, Eid (2011), posit in his study that the Saudi Government's support was recognized as an important element in the development and growth of local e-Commerce. According to Eid's study, some Saudi citizens believe in the importance of the government's role. Some of the respondents in his study commented on the diffusion of e-commerce by government and private accreditation in providing the basic facilities such as a house address for every citizen, to be used online for accurate delivery of products and documents and special services. If there is no reliable postal service, there will be no e-government (Kabango \& Asa, 2015).

From the foregoing discussion, it is crystal clear that e-commerce is attested to be an appropriate alternative for people who need to shop and transact from the confines of their home. With the globalization phenomenon, e-commerce contributes to the removal of geographical boundaries; it enables people and businesses to reach the global market. Not only big companies are taking advantages of the e-commerce, SME are also accessing global market in addition to their local markets. SMEs can sell and purchase products and services from the global market. Along with all these advantages can be mentioned also the time restriction removal as well as working days (no Saturday, no Sunday). This implies the significant increase of sales and profit, with all the above comments in mind it is vital for every country to adopt and implement good, clear and attractive strategies of ecommerce. Unfortunately, up to now, only advanced economies are using secure e-commerce while others such as Sierra Leone and several other African countries, still not yet perceived the advantage and the necessity of selling a good e-commerce policy. This study will be used as a tool to guide policy makers, entrepreneurs and businesses to learn from others experiences and make good decision at the right time. In addition, this study will be a contribution to the growing body of research in the area of e-commerce as it tends to look at the moderating role of geographical location which has been neglected in the existing literature.

\subsection{Theoretical Framework}

In this study we use Technology-Organization-Environment (TOE) framework of Tornatzky and Fleischer (1990) who assumed a generic set of factors to predict the likelihood of E-Commerce adoption. The theory suggests that adoption is influenced by technology development (Kauffman \& Walden, 2001), organizational conditions, business and organizational reconfiguration (Chatterjee, et. al., 2002), and industry environment (Kowtha and Choon, 2001).

The relationship therefore describes the association between the independent variables and the dependent variable. Thus the framework presents a suitable model to explore how e-commerce adoption is affected by technological barriers, organisational barriers and environmental barriers, and also account for the moderating role of geographical location of their impact on e-commerce adoption. 


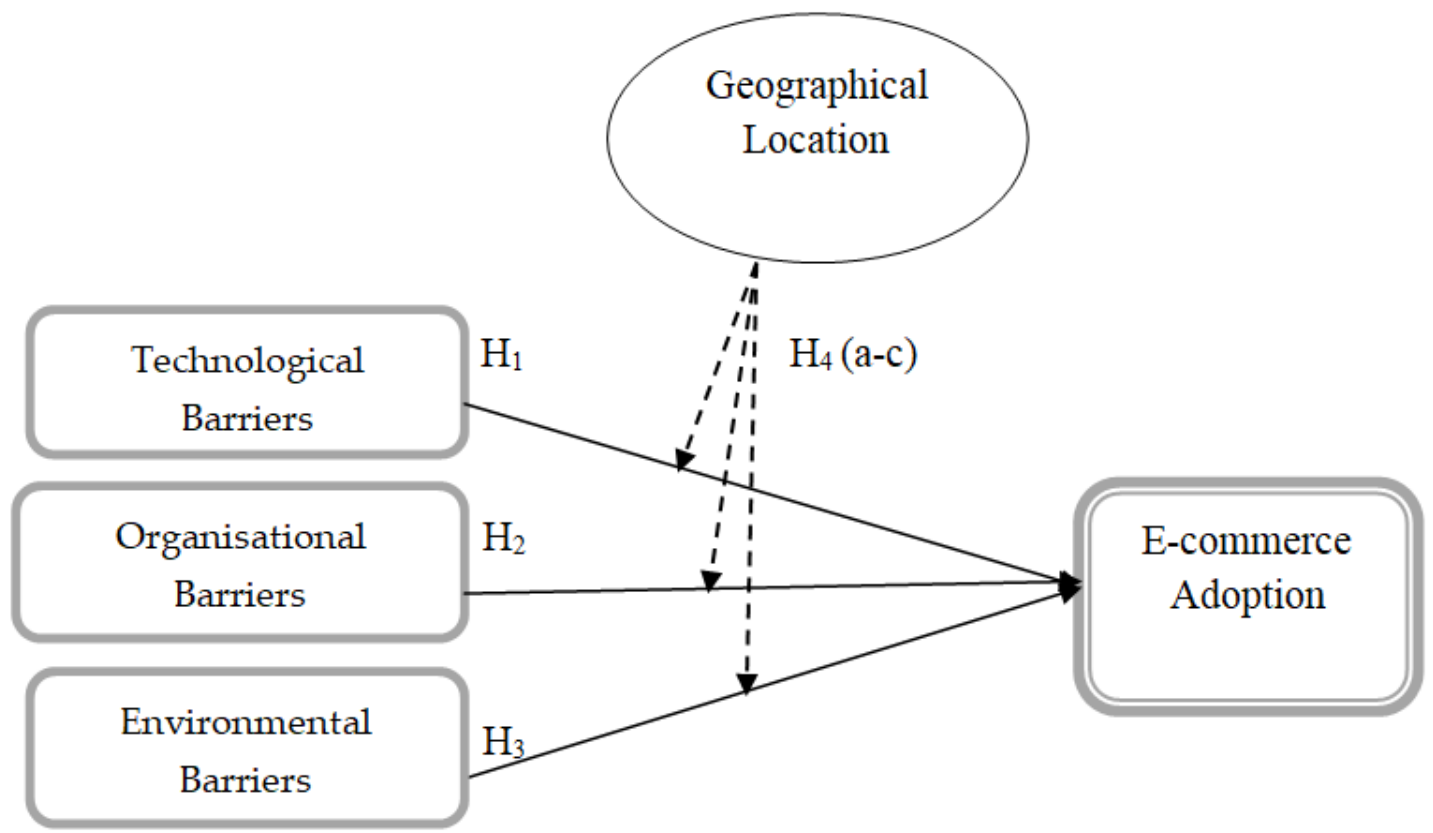

Figure 1: Framework of the hypothesized model

\subsubsection{Hypothesis}

Based on the framework given above, the following hypotheses were formulated:

- $\quad \mathbf{H}_{1}$ : Technological barriers negatively affect e-commerce adoption among SMEs

- $\quad \mathbf{H}_{2}$. Organisational barriers negatively affect e-commerce adoption among SMEs

- $\quad \mathbf{H}_{3}$. Environmental barriers negatively affect e-commerce adoption among SMEs

- $\quad$ Ha. The effect of Technological barriers on e-commerce adoption is stronger for rural SMEs than for urban SMEs

- $\quad \mathbf{H}_{\mathbf{4 b}}$. The effect of organisational barriers on e-commerce adoption is stronger for rural SMEs than for urban SMEs

- $\quad \mathbf{H}_{\mathbf{4 c}}$. The effect of environmental barriers on e-commerce adoption is stronger for rural SMEs than for urban SMEs

\section{METHODOLOGY}

\subsection{Instrument}

500 self-designed questionnaires were used to gather primary data from the participants. The questionnaire was divided into three parts. The first part comprised of demographic information of the respondents including their geographical locations. The second part consisted general information of e-commerce adoption, technological barriers, organisational barriers, and environmental barriers. This part consisted of 24 questions into group which were used to measure e-commerce adoption, technological barriers, organisational barriers and environmental barriers adapted from different previous studies as categorized in the model measurement in section 4.2, using 5-point Likert scale anchored from strongly disagree to strongly agree.

\subsection{Data Collection}

Data were collected through face to face interview approach. The survey was conducted on a sample of the SMEs owners in Freetown, the capital city of Sierra Leone and the provinces-three major rural districts (Bo, Kenema and Makeni). 200 questionnaires were administered in Freetown and 300 in the rural districts. Interviews were done for the reasons in line with the explanations done by Crowther and Lancaster (2009) and Veal (2005). Crowther and Lancaster (2009) stated that interview is a face-to-face questioning technique, which aimed to collect information from the respondents. They further indicated the advantages of interviews; the face-to-face questioning techniques in particular allow the researcher to provide feedback to respondents 
immediately upon collecting the data. This, in turn, enables the researcher to check the validity and relevance of data as it is collected.

\subsection{Model Specification}

The research has used correlation and multiple linear regression models to determine the relationship of the independent variables with the dependent variable. Thus in deriving this relationship for the above topic we posit that:

$$
Y=\alpha_{0}+\beta_{1} X_{1}+\beta_{2} X_{2}+\beta_{3} X_{3}+u
$$

Where; $\mathrm{Y}=$ E-commerce Adoption, $\mathrm{X}_{1}=$ Technological barriers, $\mathrm{X}_{2}=$ Organisational barriers, $\mathrm{X}_{3}=$ Environmental barriers, $\mathrm{U}=$ Error term.

To evaluate the effect of geographical location on e-commerce adoption, we augment model one (1) with geographical location variable as follows:

$$
Y=\alpha_{0}+\beta_{1} X_{1}+\beta_{2} X_{2}+\beta_{3} X_{3}+\gamma Z+u
$$

$\mathrm{Z}$ is geographical location. Subsequently, we sequentially introduce interaction terms between technological barriers and geographical location into model two (2). This enables us to examine if the effect of technological barriers on e-commerce adoption is conditional on geographical location. In other words, the sign and significance of the coefficient of such interaction term will reveal whether the effect of technological barriers on e-commerce adoption depends on the geographical location. Incorporating this, we re-write model (2) as follows:

$$
\mathrm{Y}=\alpha_{0}+\beta_{1} \mathrm{X}_{1}+\beta_{2} \mathrm{X}_{2}+\beta_{3} \mathrm{X}_{3}+\gamma_{1}\left[\mathrm{X}_{1} * \mathrm{Z}\right]+\mathrm{u}
$$

Similarly, we sequentially introduce interaction terms between organisational barriers and geographical location into model two (2) as follows

$$
\mathrm{Y}=\alpha_{0}+\beta_{1} \mathrm{X}_{1}+\beta_{2} \mathrm{X}_{2}+\beta_{3} \mathrm{X}_{3}+\gamma_{2}\left[\mathrm{X}_{2} * \mathrm{Z}\right]+\mathrm{u}
$$

Finally, we sequentially introduce interaction terms between environmental barriers and geographical location into model two (2) as follows

$$
\mathrm{Y}=\alpha_{0}+\beta_{1} \mathrm{X}_{1}+\beta_{2} \mathrm{X}_{2}+\beta_{3} \mathrm{X}_{3}+\gamma_{3}\left[\mathrm{X}_{3} * \mathrm{Z}\right]+\mathrm{u}
$$

$\boldsymbol{\alpha}_{0}=$ Slope coefficient of the model, $\beta=$ Beta coefficient of determination, $\gamma_{1}, \gamma_{2}$ and $\gamma_{3}$ are coefficient measures of the moderating role of geographical location on the relationship between technological barriers, organisational barriers and environmental barriers respectively on e-commerce adoption.

\section{IV.Presentations AND ANALysis OF RESUlts}

The theories used for the questions and answer options are presented in the literature review. In the following sub divisions the relevant theories are further rationalized and the reasons why these questions are presented are justified. This section also includes the research findings including the presentation of the answers given to the questionnaire. The general method used to solicit information from the respondents has been presented in the methodology. The aim of the questions presented in this section was to find out how the stated barriers affect e-commerce adoption in Sierra Leone followed by a regression model that shows the moderating role of geographical location.

However, prior to carrying out the hypothesis testing, we accomplished groundwork scrutiny of the data set to verify for the violations of the underlying assumptions of residual normality, heteroscedasticity, linearity and multi collinearity. The residual test analysis does not show any severe violation of the assumptions. A Statistical Package for Social Science (SPSS) version 20.0 was used to analyze the construct validity and reliability and consequently test the research hypotheses.

\subsection{Demographic Characteristics of Respondents}

This section gives the background characteristics of respondents that participated in the survey, the gender distribution of respondents that participated in the study, age, education, geographical location, and size of the SMEs in terms of number of employees were looked at. Most of these aspects are believed to relate to the variables of the study hence can affect e-commerce adoption among SMEs in Sierra Leone. A breakdown of this information is presented in table 1 below: 
Table1 Demographic characteristic of the respondents

\begin{tabular}{|l|l|l|}
\hline Gender (\%) & Education (\%) & Ownership (\%) \\
\hline Male $=61.0$ & Diploma $=50.3$ & Owner $=100$ \\
\hline Female $=39.0$ & Bachelor $=35.0$ & Employed $=0.00$ \\
\hline Age $(\%)$ & Masters $=13.0$ & Number of employees $(\%)$ \\
\hline$\leq 25=18.1$ & PhD $=1.7$ & $1-5=32.2$ \\
\hline $27-32=29.9$ & Geographical Location $(\%)$ & $6-10=22.6$ \\
\hline $33-40=23.2$ & Rural $=63.8$ & $11-15=17.5$ \\
\hline $41-48=18.9$ & Urban $=36.2$ & $16-20=12.4$ \\
\hline $49-51=18.9$ & & $21-25=15.3$ \\
\hline$\square 51=5.1$ & & \\
\hline
\end{tabular}

As illustrated in table 1, the demographic characteristics of respondents in this study are reported. The final sample comprised of 442 respondents (male 61.0 percent, female 39.0 percent). In terms of age structure, a good number of the respondents were aged between 27 to 32 years (29.9 percent) followed by those aged between 41 to 48 and 69 to 51. A huge number of respondents had a diploma certificate (50.3 percent), followed by bachelor degree (35.0 percent). Approximately 63.8 percent of the respondents had SMEs located in the rural areas followed by 36.2 percent of those who had SMEs located in the urban areas. This categorical variable has been treated with an utmost importance in this research as it accounted for the moderating role geographical location had on the factors affecting e-commerce adoption among SMEs in Sierra Leone. This point is very vital for this study as the characteristics of rural respondents might not be the same with those in the urban areas. 100 percent of the respondents were owners of SME. A large number of the SMEs had 1-5 employees (32.2 percent) followed by those with 6-10 employees (22.6 percent).

\subsection{Data Reliability and Validity}

The element of analysis of this research was registered SMEs holders in Sierra Leone. Out of the 500 questionnaires administered by the researchers, 442 completely filled questionnaires were collected translating to $88.4 \%$ response rate. Hence, the data collected can be evaluated using inferential statistics (Sekaran, 2000; Ormrod \& Levy, 2005). The $88.4 \%$ respondents responded to all items in the questionnaire for the main measures of the research using 5-point Likert-type scales between the range of 1 (strongly disagree) to 5 (strongly agree). We calculated an overall score for a measure by averaging ratings on items for the measure.

E-Commerce adoption was measured with twelve items and technological barriers with 4 items that were sourced from Chatterjee, et. al., (2002), Abdel Nasser H. Zaied (2012), Premkumar (2003), Ramdani et. al., (2009) and Rogers (1995) e-commerce adoption and e-commerce barrier scales. The e-commerce adoption scale $(\alpha=.903)$ evaluated SMEs owners perceptions about the adoption of e-commerce by their business. The technological barrier scale $(\alpha=.792)$ evaluated the degree of SMEs owners' perceptions about how technological inadequacy may hinder their acceptance of e-commerce adoption. We evaluated organisational barriers using a modified version of the organisational barriers scales that were taken from Alshehri M. \& Drew S. (2010), Olatokun W. \& Bankole B. (2011), Lane M. et. al., (2004) and Kapurubandara M., (2009). We selected four items from the original measures. The organisational barrier scale $(\alpha=.762)$ evaluated the degree of SMEs owners' perceptions about how organisational barriers can affect e-commerce adoption by their SMEs. Finally, the environmental barrier scales were adapted from Chitura T. et. al., (2008), Looi H., (2003), Olatokun W. \& Kebonye M. (2010) and Alshehri M. \& Drew S. (2010). The scale $(\alpha=.701)$ evaluated the degree of SMEs owners' perceptions about how the environment in which their business is operating can affect their acceptance of e-commerce adoption.

In summary, the Kaiser- Mayer-Olkin Test (KMO), which measures sampling adequacy, was done for each variable and the results showed acceptability. The average variance extracted (AVE) was also computed. In particular, the results of these statistical analyses showed that; (1) all the study variables exceeded the minimum standard of the KMO value of 0.6 and were significant in Bartlett's test of sphericity, (2) the items for each of the study variable exceeded factor loadings of 0.50 (Hair et al., 2005), and (3) all the Chronbach's $\alpha$ values were above 0.7 , which is the cut-off point (Liu, 2015). The statistical results confirmed the measurement scale of this research met the acceptable standard of reliability and validity analyses as given in Table 2 and Table 3 respectively. 
Table 2 Results of Cronbach's Alpha, KMO and AVE

\begin{tabular}{|l|c|c|c|c|}
\hline Variables & No of Item & $\begin{array}{c}\text { Cronbach's } \\
\text { Alpha }\end{array}$ & KMO & $\begin{array}{c}\text { Average Variance } \\
\text { extracted }\end{array}$ \\
\hline E-commerce Adoption & 12 & .903 & .824 & .835 \\
\hline Technological Barriers & 4 & .792 & .687 & .679 \\
\hline Organizational Barriers & 4 & .762 & .757 & 881 \\
\hline Environmental Barriers & 4 & .701 & .645 & .791 \\
\hline
\end{tabular}

Source: Authors computation

Table 3 Results of standardized item loading

\begin{tabular}{|l|c|c|}
\hline Construct & Item & Loading \\
\hline E-Commerce Adoption (ECA) & ECA1 & .786 \\
\cline { 2 - 3 } & ECA2 & .860 \\
\cline { 2 - 3 } & ECA3 & .834 \\
\cline { 2 - 3 } & ECA4 & .703 \\
\cline { 2 - 3 } & ECA5 & .799 \\
\cline { 2 - 3 } & ECA6 & .688 \\
\cline { 2 - 3 } & ECA7 & .778 \\
\cline { 2 - 3 } & ECA8 & .711 \\
\cline { 2 - 3 } & ECA9 & .732 \\
\hline Technological Barriers (TB) & ECA10 & .803 \\
\cline { 2 - 3 } & TB1 & .789 \\
\cline { 2 - 3 } & TB2 & .876 \\
\cline { 2 - 3 } & TB3 & .868 \\
\cline { 2 - 3 } & TB4 & .793 \\
\hline Organizational Barriers (OB) & OB1 & .801 \\
\cline { 2 - 3 } & OB2 & .740 \\
\cline { 2 - 3 } & OB3 & .833 \\
\cline { 2 - 3 } & OB4 & .789 \\
\hline Environmental Barriers (EB) & EB1 & .772 \\
\cline { 2 - 3 } & EB2 & .880 \\
\cline { 2 - 3 } & EB3 & .846 \\
\cline { 2 - 3 } & EB4 & .808 \\
\hline
\end{tabular}

Source: Authors computation

\subsection{Test of Hypothesis}

\subsubsection{Correlation Result}

Table 4 below illustrates the results of descriptive statistics and Pearson correlation analysis for the study variables. The table shows that the mean values for the variables are from 3.3809 to 4.0734 , suggesting that the levels of e-commerce adoption, the level of technological barriers, as well as the levels of organisational barriers and environmental barriers are ranging between these echelons. The correlation coefficients for the relationship between the dependent variable (i.e., E-commerce adoption) and the independent variables were less than 0.90 , which signifies that the data was not affected by issues that has to do with multicollinearity.

Participants in the research reported a mean level of e-commerce adoption of 3.3809 (3 is the midpoint on the 5-point Likert-type scale used). Bivariate correlations of the predictor variables with e-commerce adoption were statistically significant and in the hypothesized direction. As illustrated in Table 4, technological barriers was negatively related to e-commerce adoption $(r=-.361, p<.01)$. Thus, the first hypothesis (Hypothesis 1$)$ was supported by the study. Similarly, organisational barriers and environmental barriers were also negative and statistically significant $(r=-.171, p<.05)$ and $(r=-.279, p<.01)$ respectively. Consequently, the second and third hypotheses were also supported by the research. In a bid to test for the fourth hypothesis, regression analysis was done to ascertain the moderating role of geographical location on the relationship between ecommerce adoption and the stated barriers. These tests results are shown in table 5. 
Table 4 Descriptive statistics and correlation results for the study variables

\begin{tabular}{|c|c|c|c|c|c|c|}
\hline \multirow[t]{2}{*}{ Variable } & \multirow[t]{2}{*}{ Mean } & \multirow{2}{*}{$\begin{array}{l}\text { Standard } \\
\text { deviation }\end{array}$} & \multicolumn{4}{|c|}{ Pearson correlation analysis } \\
\hline & & & 1 & 2 & 3 & 4 \\
\hline 1 E-Commerce Adoption & 3.3809 & .73955 & (1) & & & \\
\hline 2 Technological Barriers & 3.7331 & .79487 & $-.361 * *$ & (1) & & \\
\hline 3 Organisational Barriers & 4.0734 & .58773 & $-.171 *$ & $.288 * *$ & (1) & \\
\hline 4. Environmental Barriers & 3.9181 & .61382 & $-.279 * *$ & $.258 * *$ & $-.473 * *$ & (1) \\
\hline
\end{tabular}

Note: $\mathrm{N}=442$, Significant level: ${ }^{*} p<.05$, two-tailed, $\mathrm{p}<0.01 * *$ (2-tailed). Source: Authors computation

\subsubsection{Regression Results}

Geographical location is a dichotomous categorical variable. To examine the moderating effects, we coded geographical location as a dummy variable with rural $=1$ and urban $=0$ and tested the moderating effects of geographical location according to the methodology proposed by Jaja Suteja et al. (2016). The testing results are shown in table 5. As illustrated in model 2, the moderating effect of geographical location on the relationship between technological barriers and e-commerce adoption is significant. The adjusted $\mathrm{R}^{2}$ value for e-commerce adoption increases from 0.250 to 0.333 . The significant coefficient indicates that geographical location has a stronger negative $(\beta=-.515, P<0.01)$ moderating effect on the relationships between technological barriers and e-commerce adoption, which means that technological barriers has a stronger negative effect on e-commerce adoption for rural SMEs than for urban SMEs. This result validates the acceptance of hypothesis $4 \mathrm{a}\left(\mathrm{H}_{4 \mathrm{a}}\right)$.

Similarly, as shown in model 3, the moderating effect of geographical location on the relationship between organisational barriers and e-commerce adoption is significant. The adjusted $\mathrm{R}^{2}$ value for e-commerce adoption increases from 0.250 to 0.332 . The significant coefficient indicates that geographical location has a strong negative $(\beta=-.497, P<0.05)$ moderating effect on the relationships between organisational barriers and ecommerce adoption, which means that organisational barriers has a stronger negative effect on e-commerce adoption for rural SMEs than for urban SMEs. This result validates the acceptance of hypothesis $4 \mathrm{~b}\left(\mathrm{H}_{4 \mathrm{~b}}\right)$.

Finally, as illustrated in model 4, the moderating effect of geographical location on the relationship between environmental barriers and e-commerce adoption is statistically significant. The adjusted $\mathrm{R}^{2}$ value for ecommerce adoption increases from 0.250 to 0.339 . The significant coefficient indicates that geographical location has a strong negative $(\beta=-.499, P<0.01)$ moderating effect on the relationships between environmental barriers and e-commerce adoption, which means that environmental barriers has a stronger negative effect on e-commerce adoption for rural SMEs than for urban SMEs. This result also validates the acceptance of hypothesis $4 \mathrm{c}\left(\mathrm{H}_{4 \mathrm{c}}\right)$ of the study.

Table 5 Result of regression analysis

\begin{tabular}{|l|c|c|c|c|}
\hline \multirow{2}{*}{ Variable } & \multicolumn{3}{|c|}{ Dependent variable (E-Commerce Adoption) } \\
\cline { 2 - 5 } & Model1 & Model 2 & Model 3 & Model 4 \\
\hline Constant & $1.552^{* *}$ & $1.251^{* *}$ & -.803 & $-.844^{* *}$ \\
\hline Technological Barriers & $-.501^{*}$ & $-.531^{* *}$ & $-.397^{*}$ & $-.365^{*}$ \\
\hline Organizational Barriers & $-.490^{* *}$ & -.437 & .118 & $-.322^{* *}$ \\
\hline Environmental Barriers &.$-407^{* *}$ & $-.288^{*}$ & $-.212^{* *}$ & $-.331^{* *}$ \\
\hline$(\mathrm{TB} * \mathrm{Z})$ & & $-.515^{* *}$ & & \\
\hline$(\mathrm{OB} * \mathrm{Z})$ & & & $-.497^{*}$ & \\
\hline$(\mathrm{EB} * \mathrm{Z})$ & & & & $-.499^{* *}$ \\
\hline $\mathrm{F}$ & $24.691^{* *}$ & $25.496^{* *}$ & $32.813^{* *}$ & $32.782^{* *}$ \\
\hline $\mathrm{R}^{2}$ & .258 & .344 & .346 & .353 \\
\hline Adj. $\mathrm{R}^{2}$ & .250 & .333 & .332 & .339 \\
\hline
\end{tabular}

Note: $\mathrm{N}=442$, Significance at $* p<.05$, two-tailed. ${ }^{*} \mathrm{p}<0.01$, two-tailed; $\mathrm{TB}=$ Technological Barriers, OB $=$ Organisational Barriers, EB = Environmental Barriers, $Z=$ Geographical location. Source: Authors computation

\section{DISCUSSION OF THE RESULTS}

This sub section discusses the results. The data, extracted from the responses in the questionnaires administered to the targeted respondents, as well as some information extracted from various publications and the literature review provide the basis for the results and discussions in this study. The study examined how technological, organisational and environmental barriers serve as major challenges for e-commerce adoption 
among SMEs in Sierra Leone and in the process explores the moderating role of geographical location between them. Following a line of investigation on the empirical data, the following findings are purported:

First, technological barrier has a significant effect on e-commerce adoption. This finding is in conformity with previous studies demonstrating that technological factor can predict e-commerce adoption in least developed countries (Premkumar, 2003; Rogers, 1995). Technological barrier is the most challenging barrier to e-commerce adoption among SMEs. This finding indicates that technological barrier has a major drawback in ecommerce adoption. Thus, improving the technological environment of e-commerce applications can contribute in enhancing their adoption intention by SMEs. Particular proportions, such as "internet access," ICT affordability, ICT complexity, and perceived advantages of technology, are value propositions of e-commerce adoption (Rogers 1995; Thong 1999; Ramdani et al., 2013). Consequently, to advance the service value of these factors, SMEs owners can expand on their intent in adopting e-commerce.

Second, consistent with previous studies (Olatokun W. \& Bankole B. 2011; Lane M. et. al., 2004; Alshehri M. \& Drew S. 2010), the negative effect of organisational factors on the adoption of e-commerce has been supported in this study. These findings imply that SMEs with a low level of ownership support, ICT experience, lack of available resources, and lack of computer skills are more averse to accept e-commerce adoption. Thus, SMEs owners can consider these barriers as key factors to help develop and promote their inclination towards ecommerce adoption. ICT growth of SMEs is claimed to be deprived by technical knowledge and economic costs (Cragg and King 1988). Moreover, support from SMEs owners are relatively limited not because they don't want to provide support, but they lack the experience and skills as most of the respondents are just diploma holders. Thus, SMEs owners can consider providing training for themselves so as to increase their capacity in ecommerce adoption.

Thirdly, With regard to environmental barriers; lack of competition among SMEs, lack of regulation, lack of ICT support in the environment and lack of internet security in the environment have a negative effect on ecommerce adoption among SMEs. This finding indicates that SMEs owners care significantly about environmental barriers. The negative effect of environmental barriers on e-commerce adoption has been validated by other studies (Looi H., 2003; Olatokun W. \& Kebonye M. 2010). Thus government's role is important to facilitate the essential environmental requirements for the development of E-Commerce such as providing robust secure online payment options, ensuring a solid ICT infrastructure.

Finally, the moderating effects of geographical location on the relationship between the stated barriers and e-commerce adoption have been examined. The results show that technological barrier has a stronger effect on e-commerce adoption for rural SMEs than for urban SMEs followed by environmental barriers and organisational barriers respectively. Earlier studies pointed out that geographical location of SMEs can be a motivation or barrier to technology infrastructure development. In some regions of a country, technology infrastructures can be difficult to develop just as in the case of rural region in Sierra Leone and thus showing a strong negative effect on e-commerce adoption. In consequence, the findings draw attention to the relevance of geographical location in e-commerce adoption. An important policy implication immerging from this study is that business administrators should not underestimate the power of geographical location in influencing ecommerce adoption.

\subsection{Implications}

\subsubsection{Theoretical implications}

This study provides implications for researchers as well as for SMEs owners. For researchers, this study is likely to be among the first to look at the barriers to e-commerce adoption with a moderating effect of geographical location. Previous researches focused mainly on the barriers to e-commerce adoption and overlooked the significant role of geographical location in moderating the effects of those barriers on ecommerce adoption. This research fills this gap. Majority of the studies investigated barriers to e-commerce adoption were carried out on western societies and so far limited literature is available in Sub-Sahara Africa context. So, this research geared towards filling this gap by examining the extent e-commerce adoption is affected by technological, organisational and environmental barriers in Sierra Leone vis-à-vis that of other SubSahara African economies. We found that technological barriers, organisational barriers and environmental barriers, all negatively influence e-commerce adoption. Finally, incorporating the moderating role of geographical location, the results show that rural SMEs are more negatively affected by e-commerce adoption than urban SMEs. These factors were not tested in previous e-commerce adoption studies. This research 
therefore expands the e-commerce adoption literature as the finding indicates that the barriers may modify rural SMEs' e-commerce adoption, which enriches e-commerce research.

\subsubsection{Practical implications}

Some important practical implications exist. First, the most burning task for e-commerce adoption is to improve on the barriers. Even though these barriers are difficult to overcome, they can augment e-commerce adoption intention. To highlight the importance of e-commerce adoption, the authorities in charge and SMEs owners can take measures in two folds. On one hand, they should increase technological readiness; improvement in the SMEs organisational set up, and overall improvement in the business environment. For example, the government can emphasize the convenience of e-commerce adoption to facilitate business activities. On the other hand, the authorities in charge should decrease SMEs owners' perception about ecommerce adoption. For instance, the government can improve the business environment through certain mechanisms to reduce SMEs aversion on e-commerce adoption.

Second, the results demonstrate that rural SMEs are more negatively averse toward e-commerce adoption because of their geographical location. Improvement on the barriers may change rural SMEs' reluctance of ecommerce adoption. The current barriers are a bit improved for urban SMEs, such as internet access, ICT affordability and ICT support in the environment etc., but these barriers are less improved specifically in the rural areas for rural SMEs. Thus, these barriers should also be improved in the rural areas so as to increase ecommerce adoption among rural SMEs.

\subsection{Limitations and Further Research Directions}

This study has certain limitations as in any research. Firstly, the research made up of 442 respondents in Sierra Leone, the sample might not be adequate for generalization. Second, the research aggregated the barriers into three major group i.e. technological, organisational and environmental barriers. The disaggregation of these barriers may yield appealing result as the magnitude of each of them will be measured.

Thirdly, this research only examined the moderating effects of geographical location. Other dichotomous categorical variables such as age, gender, education, and experience may also be considered. Finally, this research was conducted in Sierra Leone. As the barriers to e-commerce adoption vary among countries across the globe, the conclusions might not be the same when the research model is applied to other countries. It is suggested that further researchers take the current constraints into consideration and use different measurement scales to measure the connection between the barriers and e-commerce adoption.

\section{VI.CONCLUSIONS}

The study in essence sought to unearth the challenges faced by SMEs in adopting e-commerce in Sierra Leone and in the process accounts for the moderating role of geographical location on the relationship between them. The study contributes to e-commerce literature by exploring the relationship between technological barriers, organisational barriers, environmental barriers and e-commerce adoption in the Sierra Leone context. Theories and literatures were reviewed to develop a suitable model for e-commerce adoption and the model (TOE) was developed based on e-commerce adoption research literature that are mostly focused in the US setting.

The reliability and validity measurement scales were used to measure the relationship between the stated barriers and e-commerce adoption, and the moderating effect of geographical location in the model. Results of testing the model using correlation and regression analysis discovered two important findings: first, technological barriers, organisational barriers and environmental barriers have a direct negative relationship with e-commerce adoption which supported the hypotheses of the study. The results further show that technological barrier is the most challenging barrier of e-commerce adoption followed by environmental and organisational barriers respectively. Second, the moderating effects of geographical location were tested, which showed that the barriers have a more negative effect on e-commerce adoption for rural SMEs than for urban SMEs. The authorities can offer more conducive business environment, and focus more attention to rural SMEs' for expanding their e-commerce adoption capacity. 


\section{REFERENCES}

[1] Abdel Nasser H. Zaied. Barriers to E-Commerce Adoption in Egyptian SMEs. Information Engineering and Electronic Business, 3, 9$18,2012$.

[2] Achrol, R. S., \& Kotler, P. Marketing in the Network Economy. The Journal of Marketing, 63,146-163, 1999.

[3] Alshehri M. \& Drew S. Challenges of e-Government Services Adoption in Saudi Arabia from an e-Ready Citizen Perspective, World Academy of Science, Engineering and Technology, 66: 1053-1059, 2010.

[4] Brian Foster. (2013). Internet entrepreneur. [Online]. Available: http://www.business-solutions- and-resources.com/internetentreprene ur.html

[5] Cindy Millman, W. C. Wong, Z. Li, and H. Matlay, Educating students for e-entrepreneurship in the UK, the USA and China, Industry and Higher Education, 2009, vol. 23, no. 3, pp. 243-252.

[6] Chatterjee, D., Grewal, R., \& Sambamurthy, V. (2002). Shaping up for e-commerce: Institutional enablers of the organizational assimilation of web technologies. MIS Quarterly, 26(2), 65-89.

[7] Crowther, D. \& Lancaster, G. (2009) Research Methods: a concise introduction to research in management and business consultancy. (2nd ed.). Amsterdam: Butterworth-Heinemann

[8] Chitura T., Mupemhi S., Dube T. \& Bolongkikit J. (2008). Barriers to Electronic Commerce Adoption in Small and Medium Enterprises: A Critical Literature Review, Journal of Internet Banking and Commerce, 13(2); 1-13.

[9] Cragg, P. B. and King, M. (1988). Organizational characteristics and small firms' performance revisited. Entrepreneurship Theory and Practice, 13, 49-64.

[10] Chowdhury, A. (2003) "Information Technology and Productivity Payoff in the Banking Industry: Evidence from the Emerging Markets", Journal of International Development, 15, 693-708

[11] Eid, M. I. (2011). Determinants of e-commerce customer satisfaction, trust, and loyalty in Saudi Arabia. Journal of Electronic Commerce Research, 12(1), 78-93.

[12] Hair, J.F. et al., (2005) Multivariate Data Analysis, New Jersey: Prentice Hall International Inc.

[13] Jaja Suteja, Ardi Gunardi, Annisa Mirawati (2016). "Moderating Effect of Earnings Management on the Relationship between Corporate Social Responsibility Disclosure and Profitability of Banks in Indonesia", International Journal of Economics and Financial Issues, Vol. 6 No. 4, pp 1360-1365.

[14] Kabango, C.M.\& Asa, A.R.(2015). Factors influencing e-commerce development: Implications for the developing countries. International Journal of Innovationand Economic Development. 1,(1), 64-72.

[15] Kauffman, R., \& Walden, E. (2001). Economics and electronic commerce: Survey and directions for research. International Journal of Electronic Commerce, 5(4), 5-116.

[16] Kapurubandara M., (2009). A framework to e-transform SMEs in Developing Countries‘, Electronic Journal of Information Systems in Developing Countries, 39(3): 1-24.

[17] Kowtha, N. \& Choon (2001). Determinants of Website Development: A Study of Electronic Commerce in Singapore. Information and Management 39(3), 227-242

[18] Lane M., Vyver G., Delpachitra S. \& Howard S. (2004). An electronic commerce initiative in regional Sri Lanka: the vision for the central province, Electronic commerce Portal, Electronic Journal on information systems in Developing countries, 16(1): $1-18$.

[19] Liu, S. (2015), "How team risk and planning and control risk moderate the effects of clan and self control on the process performance of IT projects: the perspective of user liaisons", Information Development, Vol. 31 No. 1, pp. 27-39.

[20] Looi H., (2003). A model of factors influencing electronic commerce adoption among small and medium enterprises in Brunei Darussalam, International Journal of information technology, 10(1): 72-87.

[21] MacGregor, R. C., \& Vrazalic, L.(2005). Role of Small-Business Strategic Alliances in the Perception of Benefits and Disadvantages of E-commerce Adoption in SME. In M. Khosrowpour (Ed.), Advance Topic in Electronic Commerce (Vol. 1). London: Idea Group publishing.

[22] Molla, A., \& Licker, P. S. (2004). E-commerce adoption in developing countries: a model and instrument. Information \& Management, 42(6), 877-899

[23] Molla, A., \& Licker, P. S. (2005a). Perceived e-readiness factors in e-commerce adoption: an empirical investigation in a developing country. International Journal of Electronic Commerce, 10(1), 83-110.

[24] Molla, A., \& Licker, P. S. (2005b) "e-Commerce adoption in developing countries: a model and instrument", Information and Management, Vol. 42 No. 6, pp. 877-899. 
[25] OECD. (2002). OECD small and medium size enterprise outlook. www.oecd.org

[26] Olatokun W. \& Kebonye M. (2010) e-Commerce Technology Adoption by SMEs in Botswana, International Journal of Emerging Technologies and Society, 8(1): $42-56$.

[27] Omrod, T. J., \& Levy, Y. (2005). A framework of problem-based research: A guide for novice researchers on the development of a research-worthy problem. Informing Science: The International Journal of an Emerging Transdiscipline, 11, 17-33

[28] Rayport, J. F., \& Jaworski, B. J. (2001). e-Commerce. New York: McGraw-Hill/Irwin/MarketspaceU.

[29] Rahayu. R \& Day. J (2015). Determinant Factors of E-commerce Adoption by SMEs in Developing Country: Evidence from Indonesia. Procedia Social and Behavioral Sciences. 195, 142-150.

[30] Ramdani,B., Kawalek,P. \& Lorenzo,O. (2009). Knowledge management and enterprise systems adoption by SMEs: Predicting SMEs' adoption of enterprise systems. Journal of Enterprise Information Management, 22(1/2),10-24.

[31] Rina (2016). Challenges and Future Scope of E-commerce in India. International Journal of Emerging Trends \& Technology in Computer Science (IJETTCS). 5,2, 232-235

[32] Rogers EM. (1995). Diffusion of Innovations (4th edn) Free Press, New York.

[33] Shahriari. S, Shahriari. M \& gheiji, S. (2015). E-commerce and it impacts on global trend and market. International journal of research-granthaalayah.3(4) 49-55.

[34] Sekaran U (2000). Research Methods for Business: A Skill Building Approach (John Wiley and Sons Inc.) New York.

[35] Tamilla Mavlanova (2014). "The effect of cultural values on the perceptions of architectural quality of websites in e-commerce," presented at the SIGHCI Conference on Human Factors in Computing Systems, 2014

[36] Tan, J., Tyler, K., \& Manica, A. (2007) "Business-to-business adoption of e-Commerce in China", Information and Management, Vol. 44 No. 3, pp. 332-351

[37] Thong JYL (1999). An integrated model of information systems adoption in small business. Journal of Management Information Systems 15(4), 187-214.

[38] Tornatzky L. G. and Fleischer M., The processes of technological innovation. Lexington, MA: Lexington Books, 1990.

[39] UNCTAD - United Nation Conference on Trade and Development. (1999). "Can Electronic Commerce be an Engine for Global Growth?" Electronic commerce and the integration of developing countries and countries with economies in transition, International Trade, 19-23 July 1999, Geneva.

[40] Veal, C. A. (2005). Advanced and multivariate statistical methods: Practical application and interpretation. Los Angeles, CA: Pyrczak Publishing 